\title{
IJTARP
}

International Journal of Transactional Analysis

$12(1), 25-34$

https://doi.org/10.29044/v12i1p25

Research \& Practice

This work is licensed under a reative Commons Attributic
International License.

\section{Passivity in Education}

\section{(C) 2021 Piotr Jusik}

\begin{abstract}
The author addresses the occurrence and implications of passivity within the educational environment. After reviewing the theoretical background within the TA literature, he reports several research studies before identifying helpful approaches to tackling such passivity. He includes three case studies, complete with suggestions and diagrams of ways in which overadaptation may be resolved.
\end{abstract}

\section{Key Words}

passivity, discounting, transactions, ego states, symbiosis, overadaptation, research

\section{Introduction}

Passivity (Schiff and Schiff 1971) is a major challenge for practitioners in all fields of TA: for psychotherapists passive behaviours contribute to a client's maladjusted script patterns (Cornell, 1988; English 1977); for organisational consultants it means having to confront inefficient dynamics (Berne, 1963) that limit the system's capacity to turn the vision and mission of the organisation into a tangible reality; for counsellors passivity results in the reduced access to individual or group resources (Fassbind-Kech 2013) and therefore leads to lower levels of autonomy (Berne 1964). In terms of education, passivity undermines the success of teaching and learning, and thus reinforces learners' limiting beliefs about self as a learner, the roles of teacher and student, and the function or outcome of learning (Barrow 2009).

Research is an important aspect for many schools of psychology but there are considerable differences in the ways they lend themselves to evidence-based study. TA is a mixture of cognitive-behavioural and psychodynamic approaches (Schlegel 1998) and some of its concepts are more measurable than others. For instance, passive behaviours can be more easily observed and quantified than intrapsychic dynamics such as discounting (Mellor and Schiff 1975). Nonetheless, it is important to integrate various epistemological perspectives to enhance the processes of teaching and learning. This article will explore several aspects of educational passivity from a theoretical, evidence-based and practical perspective.

If TA is to genuinely make an impact in educational practice, it is vital that educators are fully aware of "the potential for passivity and symbiosis that is typical of schooling models of learning" (Barrow 2009 p. 301). There are many ways of confronting symbiotic invitations (Wayne 1976) to consistently promote students' full awareness of their Adult capacities. However choosing the right course of action is challenging. In view of that, this article will discuss the theoretical background of passivity from an educational perspective concerning both teachers and students, along with practical implications and application.

\section{Theoretical Background of Passivity}

The concept of passivity within TA originated within the field of psychotherapy and since its beginning has made its way to other applications of TA. The underlying mechanisms of passive behaviours involve discounting and the re-creation of past symbiotic relationship patterns that confirm outdated 'dependency contracts', which maintain maladjusted frames of reference (Schiff and Schiff, 1975) and diminish problem solving capacities. People discount internally aspects of self, other or the situation which provides them, along with grandiosity (Schiff and Schiff 1971), with justifications for their actions (or nonactions!). Passive behaviours are categorised (Schiff and Schiff 1971) into the following: doing nothing, overadaptation, agitation, incapacitation and violence.

Stewart \& Joines (2009) emphasised that passivity occurs when an individual ceases to take effective actions that would contribute to the solution of a problem. Educationally speaking, "passivity will occur when the student ceases to be active or ceases to provide information about himself" (Jagieła, 2004, p. 87); for instance, when a student responds to a 
teacher's question with silence, rather than admitting they do not understand and asking for an explanation. The aforementioned authors provide a description of passivity along with relevant psychodynamic mechanisms, though they lack an evidence base and do not place their ideas in a wider context of other psychological theories.

Passive behaviours do not arise in isolation but result from cultural scripting for passivity (Campos 1975) and collectively add to the formation of 'institutional discount structures' that unite to reinforce limiting script beliefs that lead a child to abdicate their problem-solving capacities in favour of adaptation to parental powers. Consequently, effective actions, including teaching and learning, are thwarted by a basic lack of trust in our powers that would otherwise help us to take charge of the environment. Campos stresses the importance of challenging these unhelpful patterns, especially the Don't Be You scripting message passed on at school that alienates us from the creative capacities of the Child. He extends the original thinking about passivity by placing it in an institutional context and providing a perspective that links early script decisions with the formation of social structures.

Furthermore, passivity can take many forms, one of which is hyperactivity, as described by Edwards (1979), who highlights that hyperactive behaviours result from a combination of medical, social, emotional and nutritional causes. She points out that doing nothing and overadaptation are most likely to go unnoticed due to the tacit agreement of the social environment in perpetuating these behaviours. On the other hand, agitation and incapacitation and violence tend to be seen as the most problematic because they generate considerable discomfort in the people surrounding the child. Additionally, when considering long-term problems, the passivity is taken for granted by all due to the social/emotional components of the situation that stem from the underlying, and contextually reinforced, symbiosis (Schiff and Schiff 1971). Thus, when making interventions, a TA practitioner needs to ask themselves: "How does the family system support the passive behaviour?" (Edwards, 1979, p. 61) in order to define the contribution of each family member to the creation and maintenance of the situation.

Schmid and Messmer (2005) consider the notion of responsibility in organisations as a polar opposite to passivity, although they do not state this explicitly. Their focus is on systems of responsibilities and organisational design, rather than education, and therefore their thinking could not be extrapolated and applied directly to educational practice. Hay (2009) translated the discount matrix into an accessible description of patterns of discounting and linked these to corresponding discounting behaviours and alternative responses in a model she called Steps to Success. Her ideas are applicable in the context of organisational learning and provide a clear framework for tackling passivity to the extent that the learner is motivated and can understand the model. Hay's approach could not be applied with younger learners because only students above the age of 15 were able to grasp the abstract conceptualisation necessary.

Overall, TA literature offers a description of passivity from a psychotherapeutic perspective, placing it in the realms of games. For instance, Ingram (1980) shows an analysis of passive games, which could be applied to some extent in the counselling field, but not really in other areas of TA. Consequently, there is a need for further developments in the area of educational passivity in order to identify strategies that would enhance the process of teaching and learning.

\section{Evidence Based Considerations}

In order to consider passivity further, it is useful to review some pieces of research that quantify passive behaviours and therefore provide an evidence base for the theoretical claims. Assessing the scale, frequency and distribution of passivity in relation to other contributing factors will enable us to evaluate this TA concept through data.

Fine, Covell and Tracy (1978) carried out research on the effects of TA training on teacher attitudes and behaviour. Their sample consisted of 18 teachers, though the data did not cover the full range due to incomplete questionnaires. The authors used the following three questionnaires:

- 28 item self-reported Personal Orientation Scale for Teachers (Fine, 1975) measuring scores representing the four life positions (Berne 1962);

- 20 item self-reported Pupil Control Ideology Questionnaire (Hoy \& Blankenship, 1972) measuring the teachers' tendency to employ controlling versus non-controlling practices of student education;

- 18 item self-reported Social Climate Inventory of the educational environment as either open and accepting or closed and negative.

Throughout the training the researchers introduced the experimental teachers to TA concepts such as structural and transactional analysis, life positions, stroking, time structuring, games, rackets, discounting, passivity, and briefly scripts. The specific TA concepts are not referenced in the research, however 'Born to Win' (James and Jongeward 1971) was cited as the base for designing group activities for the teachers.

While passive behaviours were not their main focus of study, the findings indicate that TA training resulted in 
a significant increase in the I'm OK, You're OK position and contributed to teacher self-awareness. Furthermore, in TA terms, the following outcomes were reported :"(a) greater awareness of own behaviour and greater ability to change it. (Includes awareness of their ego state transactions with children.); (b) more listening to children and awareness of their needs. (Includes awareness of what strokes children need and were inviting.); (c) more awareness of how they had been hooked into games and how to stay out of them; (d) greater responsibility given to students." (Fine et al. 1978, p. 238). This study does not address passivity directly, although the findings suggest that training teachers in several TA concepts does decrease the potential for passive behaviours, as indicated by the increased selfawareness of the study participants. Taking account of the existence of particular behaviours is the first step to reduce discounting and, by implication, passivity. The research by Fine et al. suggests that providing teachers with a basic working knowledge of TA concepts reduces the potential for the occurrence of educational passivity.

Thweatt and Miller (1979) also investigated the effects of TA training delivered in lectures and in so-called 'Labs' with the objective of promoting "growth and change as well as learning" (p. 290) by combining teaching with counselling. The TA Labs curriculum contained 'an expanded TA101', however there were no more details provided regarding the TA concepts taught. The researchers investigated changes in student behaviour and attitude at the beginning and end of the course by considering the following variables:

- Present Tense versus Past or Future Tense statements as indicators of contact and intimacy in the here and now;

- Tentative versus Decisive statements as indicators of growth;

- Accepting Responsibility versus Assigning Responsibility as indicators of passivity through 'Cop-outs';

- Feelings versus Cognitive Statements as indicators of intimacy and growth of awareness

- Stroking versus Discounting as indicators of growth;

- Clear Thinking versus Confused Thinking as indicators of clarity, growth and Adult processing.

The authors investigated three groups: "Section one used some TA, section two used a variety of personality theories, none of which were TA, and section three used TA exclusively" (p. 291). The samples size was 23. For the purpose of comparison, only Sections 2 and 3 were compared. The TA group showed the largest increase of the here-and-now statements, a reduction in 'what-ifs' statements, which were replaced with self-disclosure, and an increase in stroking. Both groups showed an increase in accepting responsibility, indicating that TA is not the only approach that can reduce discounting and passivity.

This study echoes the findings of Fine et al., suggesting that TA training reduced the potential for the occurrence of educational passivity. Thweatt and Miller used the recording of the first and last session of training and evaluated two 10-minute randomly selected segments in terms of statements corresponding to the variables outlined above. However their statistical methodology was less elaborate - they only applied the Chi Square test to assess the significance of difference between the study groups.

Zerin, Zerin and Cuiran (1997) compared stress responses of Chinese and American high school students using an 18-item instrument, with some questions addressing passive behaviours. The authors investigated 77 American and 80 Chinese females, both groups aged 16-18. Each population was divided into two groups: 49 Chinese and 48 American students responded to the checklist items concerning their family life; 31 Chinese and 29 American students responded to questions concerning their personal life with friends. Passivity questions were included in section $E$ (Behaviour Mechanisms) of the ' $Q$ ' model checklist created based on Eric Berne's original concepts. Discounting was included in the Attitude Mechanisms (Section C). Additionally, the authors provided specific references to the concepts corresponding to each section of their instrument, for instance:

- $\quad$ Passivity - Behaviours (Schiff \&Schiff, 1971, pp. 71-78; Schiff and Contributors, 1975, pp. 10-14)

- Discounts (Schiff et al., 1975, pp. 14-15)

The Chinese students reported that in stressful situations with friends, $72 \%$ do nothing, whereas with family that figure is $73 \%$. In contrast, $17 \%$ of American students reported doing nothing with friends and $16 \%$ with their family. $20 \%$ of Americans agitate with friends and $22 \%$ with family. $36 \%$ of Americans incapacitate themselves with family and only $14 \%$ with friends. $10 \%$ of Chinese students reported being violent with family and $7 \%$ with friends. $17 \%$ of American reported being violent with friends and only $2 \%$ with their family. This study provides detailed figures in a cross-cultural context; however the authors do not compare each category of passive behaviours systematically, e.g. there is not data for agitation regarding Chinese students. Nonetheless, the comparative aspect paves the way to validating some TA concepts interculturally; for example the authors state: "Compared with 
American students, Chinese students easily leave things open-ended and "do nothing" and use a "monotone" when speaking with friends and family because they inherited the old Chinese tradition." ( $p$. 253). Understanding the cross-cultural aspect of passivity could be a starting point to identifying culturally specific script messages, which could potentially lead to designing preventative measures.

The last study to be reviewed provided the most indepth analysis of passivity. The aim of the research project entitled 'Passivity at School' (Pierzchała, 2013) was to broadly describe passive behaviours within the context of the Polish education system. Pierzchała set out to identify the factors conducive to passivity, both in students and teachers. She investigated a number of variables such as:

- gender;

- $\quad$ ego states (Berne, 1961);

- tendencies to form symbiotic relationships (Schiff \&Schiff, 1971);

- $\quad$ life positions (Berne, 1972);

- satisfaction of psycho-biological hungers (Berne, 1970);

- $\quad$ student learning outcomes;

- the length of teacher classroom experience.

The psychometric tools constructed for the purpose of the study were based on the classical TA concepts indicated above and underwent a validation procedure described in detail. The variables were examined thoroughly, using statistical tests in order to ascertain the correlation between the frequency of passive behaviours and the aforementioned variables. The data gathered included 211 teacher and 333 student responses. Pierzchała devised and verified a questionnaire measuring passive behaviours on a scale of 1-120. Additionally, the quantitative data was complemented with qualitative research consisting of 34 student and 10 in-depth teacher interviews. The generic results of the study are shown in Table 1.

The main findings emphasised that overadaptation was the most common passive behaviour, both for teachers and students, as it appeared to be socially acceptable. Additionally, passivity in both groups was highly correlated; teachers and students reinforced each other's passivity through positive feedback loops. The qualitative data revealed that although the underlying mechanisms for passivity can be similar (but varied in intensity), they lead to different passive behaviours. For example the tension build up in a student due to a lesson that is perceived as boring leads to doing nothing in one lesson, but can lead to violence in another context outside of school.

\begin{tabular}{|c|c|c|}
\hline $\begin{array}{c}\text { PASSIVE } \\
\text { BEHAVIOUR }\end{array}$ & STUDENTS & TEACHERS \\
\hline $\begin{array}{c}\text { Mean values of } \\
\text { passive } \\
\text { behaviours }\end{array}$ & 58.33 & 50.04 \\
\hline \multicolumn{2}{|c|}{ Mean values for each passive behaviour } \\
\hline Doing nothing & 12.46 & 7.42 \\
\hline Overadaptation & 12.81 & 11.04 \\
\hline Agitation & 10.83 & 9.45 \\
\hline Violence & 6.82 & 7.96 \\
\hline Incapacitation & 8.01 & 9.42 \\
\hline
\end{tabular}

Table 1. Results of the study of school passive behaviours in Poland (source: Pierzchała, 2013)

Additionally, the qualitative analysis of student interviews revealed a psychodynamic rationale for the observed passive behaviours. For example, in the student interviews some stated:

"If the teacher teaches me something, then well, this is his job, this is his task, and I can't blame him. And the others will not teach and still pick on us during the lesson. But I still have half a year until I graduate..." (Pierzchała, 2013, p. 196).

"Because the teacher always screams when someone chats in the lesson, and when you defy her... she screams so much. So we keep quiet but the class is so boring that I ... I can't stand it, so I have to hold my eyes to stay awake." (Pierzchała, 2013, p. 197).

These quotes demonstrate that students respond to teachers' passivity (verbal violence in this case) with passivity (doing nothing and overadaptation), which creates interrelated positive feedback loops. These findings suggest that some educators are not particularly interested in the pupil's world and tend to avoid more intimate contact, which in turn is a contributing factor to the occurrence of educational passivity.

This study also highlighted that due to overadaptation, teacher activities often lead to feigned actions with the sole purpose of maintaining an image of professionalism. In reality, the educators reported low levels of professional satisfaction and engagement in their relationships with students. The main suggestions for decreasing passive behaviours included awareness building for teachers and students aiming to uncover their Adult motivators for the tasks 
relevant to their corresponding roles. Furthermore, in order to prevent educational passivity, Pierzchała urges educators to become aware of their ego states, to be open to form professionally intimate relationships with pupils, to identify ulterior messages and to act from a position of resourcefulness. These recommendations are consistent with the studies mentioned before, although they may be difficult to implement given the rigidity of educational systems in many parts of the world.

Pierzchała's research validates the TA concept of passive behaviours by integrating quantitative and qualitative research methods. She used a range of statistical tools (e.g. a-Cronbach and semantic differential coefficients) that enabled assessment of the measurable aspects of passive behaviours with scientific precision. The research contains detailed descriptions of the process of validating the questionnaires and thus contributes to the evidence base aspects of TA theory. Therefore, Pierzchała shows that TA has also potential for being a precise science that measures observable behaviours.

Apart from the studies mentioned here, there is little research carried out in the area of educational passivity and further work is required to construct an evidence base for TA concepts applied in education.

\section{Helpful Approaches to Tackling Passivity}

The pieces of research described before identify the necessity to confront passivity in teachers and students, as well as in the very nature of educational processes. For example, if teachers gained sufficient awareness to effectively pinpoint transactions containing discounts, they could reduce the frequency of passive behaviours. There are other works that echo these findings, which further helps to build a more coherent picture.

Babcock (1975) studied passivity amongst caregivers and provided a systemic overview, which underscored the importance of awareness building for carers. Although her focus was on carers in public health, some of her claims can be applied to teachers who may be struggling with rigid and unresponsive systems. She put forward some valuable suggestions for tackling institutional issues:

1. "Be aware of the problem.

2. Locate threats and obstacles.

3. Find ways to finagle (using devious methods to achieve one's end).

4. Seek counsel from a known finagler in your system (people who are friendly, knowledgeable and have strategic influence in the system).
5. Winners who revolt wait until they have sufficient power base.

6. Pick on a problem that is less dependent on the system.

7. Find a more comfortable sub-system." (p. 394)

Babcock instils a sense of hope by offering a set of steps necessary to confront systemic passivity. She does it playfully and invites TA practitioners to identify resources that can support them in facilitating change. By stating "There are ways to win in a system which has flaws" (p. 394), Babcock challenges the cultural scripting for passivity that becomes normalised in public systems. Theoretically speaking, these suggestions are valuable, although with the current digitalisation perpetuated by social media and remote learning resulting from the Covid-19 pandemic, public systems of healthcare and education have become quite impersonal. Apart from rigidity, there is a rampant lack of contact (both physical and psychological) which becomes a contributing factor to passivity. Therefore, it is vital to consider some communication strategies that could help to address passive behaviours.

Garcia (1982) puts forward the notion of reactivity defined as "a communication process used to clarify feelings, fantasies and intuitions, as well as for asking directly for wants and confronting others" (p.123). Although the author does not specifically place his thinking in educational terms, he underscores that "reactivity avoids passivity, symbiosis, games and rackets, and enhances closeness in relationships" ( $p$. $123)$, which is consistent with the observations coming from the aforementioned works (Pierzchała 2013; Thweatt and Miller 1979; Fine, Covell and Tracy 1978; Edwards 1979). Garcia offers an outline of a reactivity, which includes becoming aware of feeling reactions, thinking about them to identify the want and acting on the desires to experience relief. Translating this into educational practice, teachers can be aware of their needs and express them rather than supressing them, given that they might operate from the top position in the symbiosis (i.e. Parent and Adult). Furthermore, Garcia points out that closeness and intimacy are possible only if the Child feels safe and acknowledged. Therefore, educators can prevent the occurrence of educational passivity by accounting for their own relational needs (i.e. for safety) and acknowledging the needs of their students. Lastly, the author proposes a 'reactivity contract' which can be adjusted to classroom practice as a communication guideline for teachers and students.

The suggestions offered can have an impact to the extent they do not contradict the educator's script, as otherwise they will be discounted because they do not fit within their current educational frame of reference. 
Montuschi (1984) underscored that the schooling experience is often reduced to mechanical procedures that neglect the quality and meaning of the process, which results in the impoverishment of the studentteacher relationship. He identified several teacher script beliefs that undermine the process of teaching and learning, and thus also contribute to the occurrence of passivity:

- Learning Script: I'm OK only if you know everything - focusing solely on the learning outcome and neglecting the richness of the process;

- Change Script: I'm OK only if you change misplacing responsibility in the teacher and assigning none to the students for their process of learning and change;

- The Availability Script: Tell me what I have to do! - overreliance on external expertise while discounting one's resources;

- The Innovative Script: I hid my successes to show them off at the right time: and everyone will see me - avoiding sharing resources with the aim of self-promotion within the institution.

As well as identifying these script beliefs, Montuschi shows how these can be modified through, for example, discovering new meanings in the learning process, clarifying lines of responsibility, activating teacher resources from within and appropriate collaboration. The author's comments concerning teachers' script themes provide more psychodynamic depth to the issues of educational passivity and help to identify areas for specific interventions when coaching or training educators.

Barrow (2009) also refers to scripting by pointing out that schooling is a universal experience that is "fundamental in creating an individual's frame of reference regarding learning" (p. 298). Learning and schooling are not necessarily synonymous. Many of us have memories of being at school without necessarily learning anything. There are many models of learning, such as dogmatic, technological, liberal, progressive, humanistic and radical (Elias and Merriam 1980/1995; Newton 2003), that can be placed on a continuum according to their transformative features. The further the model lies from the traditional schooling framework, the greater the potential for challenging the occurrence of educational passivity. Barrow invites a sense of self-agency in educators by urging them to choose the educational model that best reflects their core values in a given situation. This approach is quite refined and enables a teacher to consider the nuances of an educational situation; however it requires a high level of self-awareness and TA training to understand and consider these concepts practically.

\section{Examples of Application}

At this point the question arises: How can TA practitioners translate these ideas into impactful interventions? The following examples are drawn from the author's experience and represent an attempt at transforming theory into practice: as such these are not evidence based and enter the realm of human subjectivities. Each type of passive behaviour (doing nothing, overadaptation, agitation, incapacitation and violence) can be confronted in many ways and the short case studies illustrate some options available, but are not, by any means, exhaustive.

\section{Case Study 1: Activating Physis via the Child when learners are doing nothing}

The author was involved in running a professional development course for teachers (Transactional Analysis Proficiency Awards for Teachers and Educators - see www.taproficiencyawards.org) in Guatemala.

When the Covid-19 pandemic wrought havoc around the world, the training had to move online via Zoom. In the Guatemalan context where Internet access is inconsistent and IT skills of teachers require enhancement, the training process was ineffective. The computer screen became a barrier that caused the teachers to lose interest, not attend and avoid the necessary tasks, such as reading or participating in group discussions (doing nothing). In order to challenge the passivity, the author took the following steps:

1. Teachers were asked to do something pleasurable and fun for their Child ego state, e.g. spend an afternoon listening to music, go for a walk, play with their children, watch an hilarious comedy, cook or paint, to name a few.

2. Each participant was invited to send a photo of their chosen activity.

3. During the next training session on Zoom, a slide containing all their pictures was shown (Photo 1 below).

4. Each course participant was asked to write one word in the chat in response to the pictures (responses included: freedom, joy, purpose, lightness, creativity, change, flow, connection)

5. The idea of physis (Berne 1971) was explained to the participants with reference to the pictures and the words. The following definition was used: "the force of Nature, which eternally strives to make things grow and to make growing things more perfect" (p. 98). By connecting the experiences of joy, meaning, connection, creativity and freedom with Berne's definition, the teachers had a felt sense of the concept of physis. 


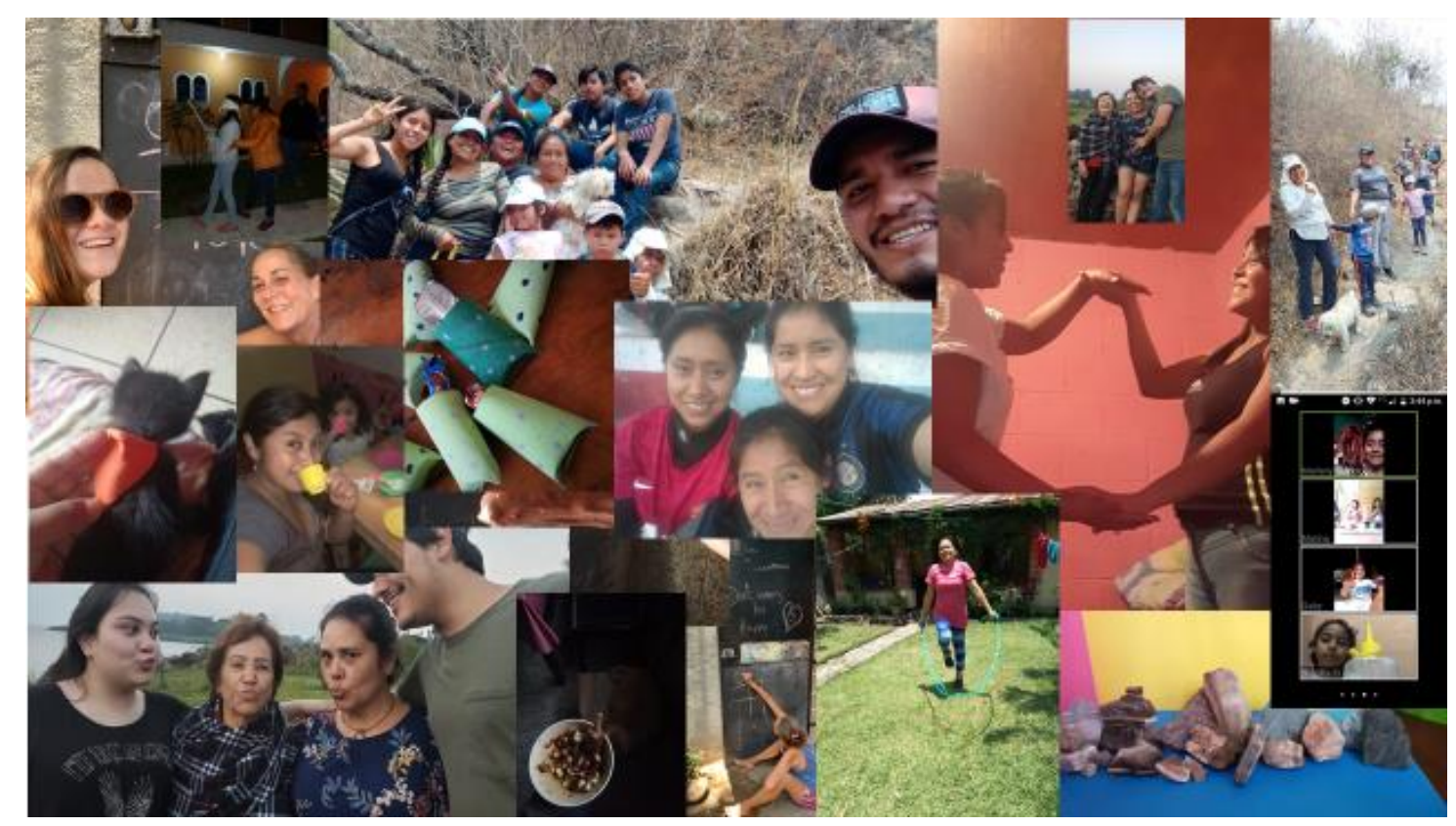

Photo 1: Assignment for Teachers - Do Something Fun

Subsequently, the teachers became more engaged, they spoke more during online discussions, asked questions and demonstrated their active learning by making links between various TA concepts. By injecting playful Child energy into the training, the author created conditions for uncovering and activating physis.

Case Study 2: Crossing transactions to confront overadaptation to the teacher

The author delivered training concerning vocational orientation for third year psychopedagogy students at a Guatemalan university. The tasks in the workshop were quite open-ended and required the participants to formulate their opinions; for example, one of the questions was "Discuss the different vocational needs of each ego state in the context of teaching". The students were working in pairs. It transpired they seemed to think that the facilitator expected particular answers from them. Instead of becoming an allknowing Parent, the author invited the students to examine their thinking and consider the validity of their claims. The following transcript, illustrated in Figure 1, exemplifies how the course participants were encouraged to value their opinions:

1. STUDENT: "Is this alright?" (student pointing to their written answer on a poster)

2. FACILITATOR: "What do you think?" (asked with curiosity)

3. ST: "I don't know..." (pleading voice, expecting an answer)
4. F: "What evidence do you need to know if you are right?' (crossing the transaction)

The author was mindful of his White Privilege (Naughton and Tudor 2006), which was another factor that contributed to the students' initial overadaptation. By treating them with respect and affirming the OKness of their thinking, the author suggested that they deserved to be listened to. They no longer had to overadapt to an imaginary standard that would diminish the value of their opinions. The students gradually opened up in the workshop and started to speak their mind and interpret the TA concepts presented to them through their own eyes, rather than trying to guess what they imagined the facilitator wanted to hear. The group left the workshop with a calm sense of self-assurance and validation.

\section{Case Study 3: Naming transactions containing discounts}

During the professional development course for teachers mentioned in Case Study 1, the participants studied the concept of script. They were asked to share with the group their favourite childhood fairy tales. The groups was quite multicultural, representing seven different cultures. Most of the educators gave answers containing examples drawn from Occidental culture, such as Cinderella, Little Red Riding Hood, and Snow White. One of the participants spoke quite apologetically about her favourite childhood fairy tales "Oh, these are just little stories from my village". This course participant wanted to overadapt to the group by diminishing the value of her cultural heritage. 


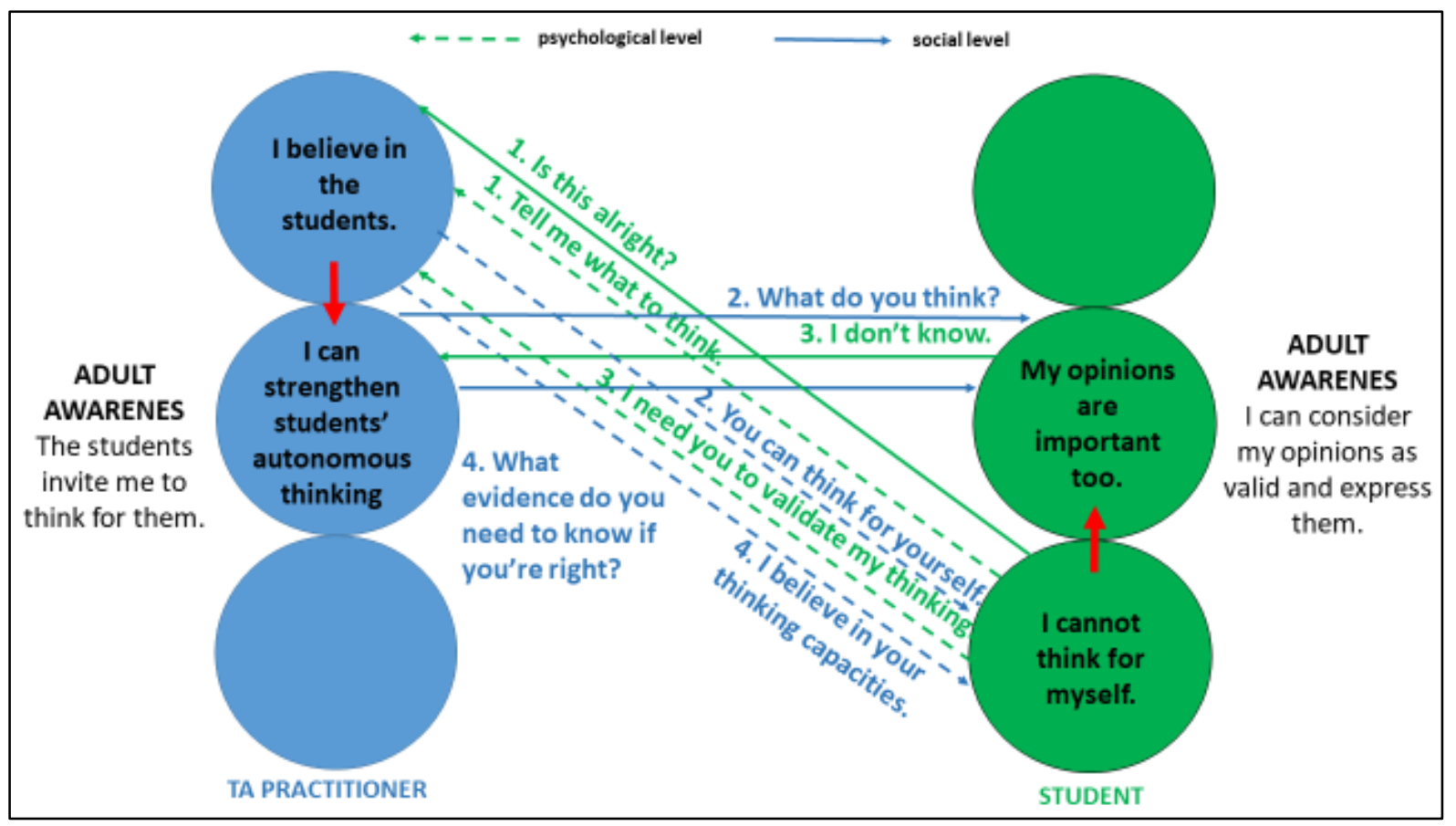

Figure 1: Crossing a Transaction to Confront Overadaptation

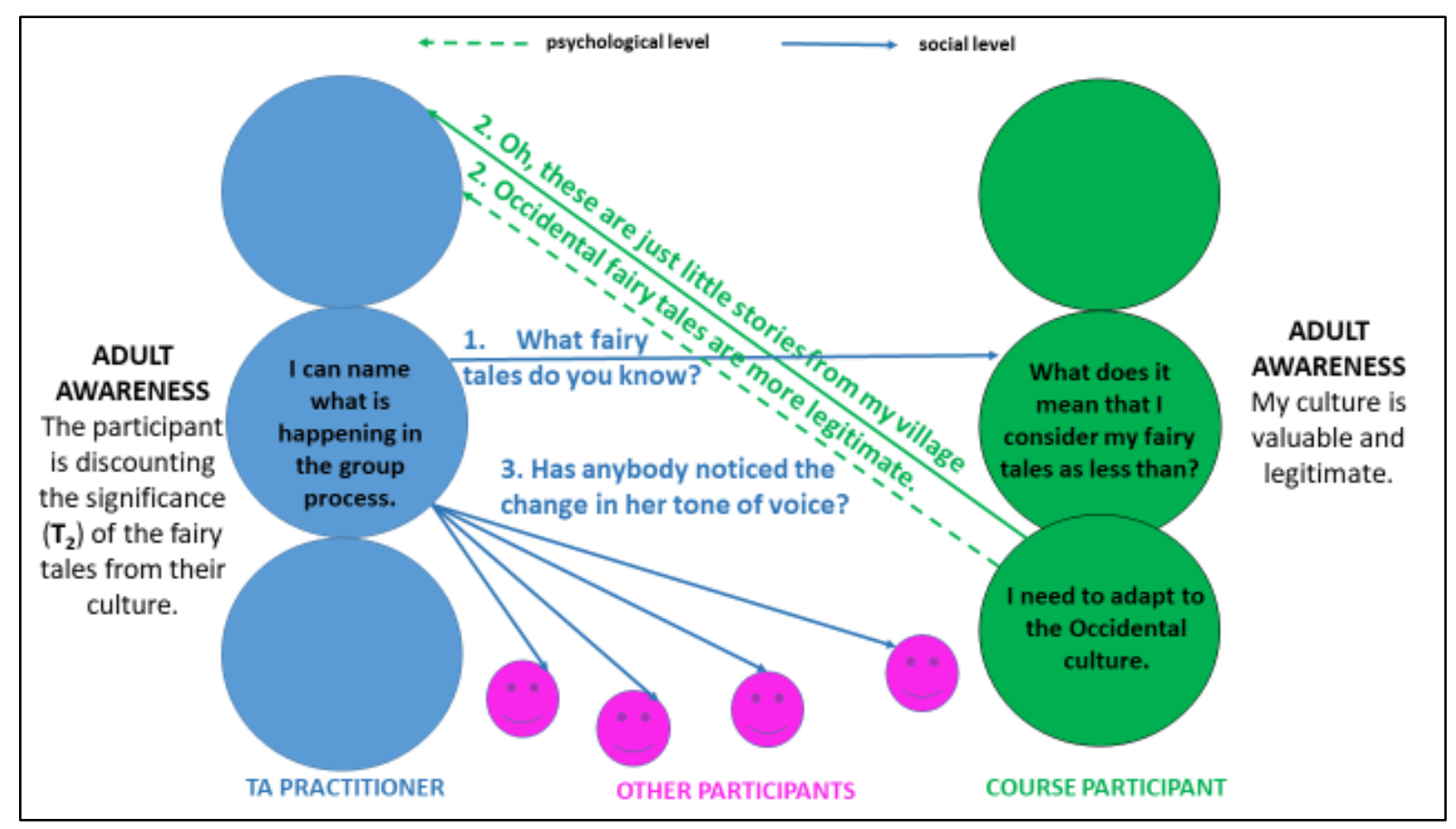

Figure 2: Naming a Transaction containing a Discount 
1. Facilitator: "What fairy tales do you know?"

2. Student: "Oh, these are just little stories from my village" (said apologetically)

3. Facilitator: "Has anyone noticed the change in her tone of voice?"

It became clear that the fairy tales representing the dominant culture (White, Occidental) were seen as more legitimate. The author named the discount that indicated that the participant wanted to overadapt to what they perceived as more valid examples of fairy tales. Following the decontamination, a discussion emerged about internalised racism, while the participant who discounted the significance of their examples was invited to celebrate their culture. At the end of the workshop many participants realised that they could value their own cultures to a greater extent. Figure 2. shows the relevant transactions.

\section{Conclusion}

To sum up, there are many options and approaches to educational passivity - it is indeed a field of TA that requires further development. The theoretical deliberations as well as the evidence-based aspects really seem to reinforce the core assumptions of TA concerning promoting OKness, closeness and intimacy as a foundation of human interactions. Educators can effectively tackle passivity provided they operate from a place of self-awareness that enables them to own their script patterns and recognise invitations to symbiosis. On the other side of the coin, teachers need to be able and supported to hand back ownership of the learning process to the student. Otherwise, it becomes a gamey interaction along the lines of 'You can't make me...'. In many parts of the world educators are burdened by increasing work demands and this article is by no means a suggestion they have to deliver even more. It is about working smarter, rather than harder, to clarify lines of responsibility. It is the author's deep belief that passivity decreases when teachers are given support to recognise their resources instead of criticism that they often face.

Piotr Jusik is a Certified Transactional Analyst (Counselling). Born in Poland and now in Guatemala, he has lived in several countries and works internationally as intercultural coach, counsellor and group facilitator. He can be contacted on peter@iflowcoaching.com

\section{References}

Babcock, D. (1975). Teaching Caregivers to Win. Transactional Analysis Journal, 5(4), 392-395. https://doi.org/10.1177/036215377500500415

Barrow, G. (2009). Teaching, Learning, Schooling, and Script. Transactional Analysis Journal, 39(4), 298-304.

https://doi.org/10.1177/036215370903900405
Berne, E. (1962). Classification of positions. Transactional Analysis Bulletin, 1(3), 23.

Berne, E. (1963). Structure and dynamics of organizations and groups. Grove Press.

Berne, E. (1964). Games people play: The psychology of human relationships. Ballantine Books.

Berne, E. (1966). Principles of group treatment. Grove Press.

Berne, E. (1970). Sex in human loving. Simon \& Schuster.

Berne, E. (1971). A layman's guide to psychiatry and psychoanalysis. Penguin Books.

Campos, L. (1975). Institutional Discount Structures. Transactional Analysis Journal, 5(1), 60-61. https://doi.org/10.1177/036215377500500113

Cornell, W. (1988). Life script theory: A critical review from a developmental perspective. Transactional Analysis Journal, 18, 270-282. https://doi.org/10.1177/036215378801800402

Edwards, S. (1979). Hyperactivity as Passive Behavior. Transactional Analysis Journal, 9(1), 6062. https://doi.org/10.1177/036215377900900113

Elias, J. L., \& Merriam, S. B. (1980). Philosophical Foundations of Adult Education (2nd ed.). Kreiger.

English, F. (1977). Let's not claim it's script when it ain't. Transactional Analysis Journal, 7(2), 130-138. https://doi.org/10.1177/036215377700700203

English, F. (1977). What shall I do tomorrow? In G. Barnes, Transactional analysis after Eric Berne (pp. 287-350). Harper's College Press.

Fassbind-Kech, L. (2013). Counseling as a Treasure Hunt. Transactional Analysis Journal, 43(1), 24-37. https://doi.org/10.1177/0362153713486101

Fine, M. (1975). The personal orientation scale for teachers. University of Kansas.

Fine, M., Covell, G., \& Tracy, D. B. (1978). The Effects of TA Training on Teacher Attitudes and Behavior. Transactional Analysis Journal, 8(3), 236239. https://doi.org/10.1177/036215377800800315

Garcia, F. (1982). Reactivity. Transactional Analysis Journal, 12(2), 123-126.

https://doi.org/10.1177/036215378201200205

Hart, W. E. (1976). Symbiotic Invitations.

Transactional Analysis Journal, 6(3), 253-254. https://doi.org/10.1177/036215377600600303

Hay, J. (2009). Transactional Analysis for Trainers (2nd ed.). Sherwood Publishing.

Hoy, W., \& Blankenship, J. (1972). A comparison of the ideological orientations and personality characteristics of teacher acceptors and rejectors of BSCS biology. Science Education, 972, 71-77. https://doi.org/10.1002/sce.3730560111

Ingram, R. (1980). Games and Passivity. Transactional Analysis Journal, 10(1), 13-15. https://doi.org/10.1177/036215378001000105 
Jagieła, J. (2004). Gry psychologiczne w szkole. Oficyna Wydawnicza Nauczycieli.

James, M., \& Jongeward, D. (1971). Born to Win: Transactional Analysis With Gestalt Experiments. https://doi.org/10.2307/583346

Mellor, K., \& Schiff, E. (1975). Discounting. Transactional Analysis Journal, 5(3), 295-302. https://doi.org/10.1177/036215377500500321

Montuschi, F. (1984). Teacher's Scripts and InService Training Programs. Transactional Analysis Journal, 14(1), 29-31.

https://doi.org/10.1177/036215378401400105

Naughton, M., \& Keith, T. (2006). Being White. Transactional Analysis Journal, 36(2), 159-171. https://doi.org/10.1177/036215370603600208

Newton, T. (2003). Identifying educational philosophy and practice through imagoes in transactional analysis training groups. Transactional Analysis Journal, 33(4), 321-331.

https://doi.org/10.1177/036215370303300407

Pierzchała, A. (2013). Pasywność w szkole: Diagnoza zjawiska z punktu widzenia analizy transakcyjnej. (Passivity at school: Diagnosing the phenomenon from the point of view of transactional analysis). Edukacyjna Analiza Transakcyjna, 2, 163.

Schiff, A., \& Schiff, J. (1971). Passivity. Transactional Analysis Journal, 1(1), 71-78.

https://doi.org/10.1177/036215377100100114

Schiff, J., \& Contributors. (1975). Cathexis reader. Harper \& Row,

Schiff, J., \& Schiff, A. (1975). Frames of Reference. Transactional Analysis Journal, 5(3), 290-294. https://doi.org/10.1177/036215377500500320
Schlegel, L. (1998). What is Transactional Analysis? Transactional Analysis Journal, 28(4), 269-287. https://doi.org/10.1177/036215379802800402

Schmid, B. (2008). The Role Concept of Transactional Analysis and other Approaches to Personality, Encounter, and Cocreativity for All Professional Fields. Transactional Analysis Journal, 38(1), 17-30.

https://doi.org/10.1177/036215370803800104

Schmid, B. (2008). Transactional analysis and social roles. In G. Mohr \& T. Steinert, Growth and change for organizations: Transactional analysis new developments (pp. 32-61). International Transactional Analysis Association.

Schmid, B., \& Messmer, \&. A. (2005). On the Way to a Culture of Responsibility in Organizations: Concepts of Symbiosis Revisited. Transactional Analysis Journal, 35(4), 324-332. https://doi.org/10.1177/036215370503500406

Stewart, I., \& Joines, V. (2009). TA Today. A New Introduction to Transactional Analysis. Lifespace Publishing.

Thweatt, \& Miller, N. (1979). Counseling through the Classroom or How to Have the Best Course in the Whole University. Transactional Analysis Journal, 9(4), 290-293. https://doi.org/10.1177/036215377900900414

Zerin, E., Zerin, M., \& Cuiran, Z. (1997). A Comparative Study of Chinese and American High School Students' Responses to Stress under Pressure. Transactional Analysis Journal, 27(4), 241255. https://doi.org/10.1177/036215379702700403 